\title{
EVIDENCIAÇÃO DOS INSTRUMENTOS DE HEDGE NAS COMPANHIAS NÃO FINANCEIRAS DE CAPITAL ABERTO BRASILEIRAS
}

\author{
Yasmin Souto Franco ${ }^{1}$, Maíra Melo de Souza ${ }^{2}$ \\ 1,2 Universidade Federal de Santa Catarina \\ ${ }^{1}$ mairameloufscegmail.com \\ ${ }^{2}$ yasminsfranco@gmail.com
}

\section{Resumo}

Instrumentos de hedge são derivativos utilizados para proteção contra as variações de valor de um ativo ou passivo objeto de hedge. Esta pesquisa possui como objetivo identificar o nível de evidenciação dos instrumentos de hedge nas companhias não financeiras de capital aberto brasileiras. Para a identificação do nível de evidenciação, foi analisada uma amostra composta por vinte companhias não financeiras, com maior total do ativo, listadas na Bolsa de Valores, Brasil, Bolsa, Balcão (B3). Na amostra, foram verificadas as Demonstrações Financeiras e Notas Explicativas, Relatório da Administração e Formulário de Referência, sendo todos os documentos referentes ao exercício social findo em 2015. O nível de evidenciação foi mensurado com base no total de requisitos preenchidos de uma lista de verificação elaborada a partir do CPC 40 (R1). Os resultados demonstram que houve maior qualidade de divulgação de informações nas Demonstrações Financeiras e Notas Explicativas relativas aos instrumentos de hedge, e que no Relatório da Administração e Formulário de Referência são divulgados menos itens, e estes de informações de caráter predominantemente qualitativas. Além disso, a partir da análise, foi possível verificar uma tendência das companhias maiores possuírem um maior nível de evidenciação dos instrumentos de hedge.

Palavras-chave: Hedge. Evidenciação. Instrumentos financeiros.

\section{DISCLOSURE OF HEDGE INSTRUMENTS IN NON- FINANCIAL COMPANIES OF BRAZILIAN OPEN CAPITAL}

\section{Abstract}

Hedge instruments are derivatives for protection against changes in the value of a hedged asset or liability. This research has as objective identified the lack of disclosure of hedge instruments in Brazilian non-financial publicly traded operations. For this, it was to analyze a sample composed by twenty non-financial e-mail, with greater total of the asset, listed in the Stock Exchange, Brazil, Stock Market, Balcony (B3). Presentations and Explanatory Reports, ii) Management Report, and iii) Reference Form. All documents used refer to the fiscal year ending in 2015. It is based on a checklist drawn up from CPC 40 (R1). The results show that there was a higher quality of information disclosure in the Financial Statements and Explanatory Notes related to hedging instruments, and that in the Management Report and Reference Form less items are disclosed, and these are predominantly qualitative information. In addition, from the analysis, it was possible to verify a tendency of the most powerful electronic systems of the type of hedge.

Keywords: Hedge. Evidence. Financial instruments.

R. Eletr. do Alto Vale do Itajaí - REAVI, v. 7, n. 10, p. 01-15, jun., 2018 


\section{Introdução}

A contabilidade é uma ciência que vem evoluindo ao longo dos séculos. Um dos fatores que possibilitam seu aprimoramento é a elaboração de normas vigentes em todo o mundo, o que confere às informações contábeis uma estrutura organizada e confiável. Nos séculos passados, a falta de padrões contábeis dava margem para manipulações dos resultados das empresas, o que foi fator contributivo para várias crises financeiras registradas pela história (HENDRIKSEN; VAN BREDA, 1999).

Como consequência disso, e por demanda dos usuários externos, criou-se a exigência, ou talvez se possa dizer a necessidade, de que as empresas divulgassem demonstrativos que obedecessem às normas de contabilidade então estabelecidas. No cenário atual de internacionalização dos mercados, a evidenciação contábil segue um padrão de convergência mundial de divulgação de informações que atendam tanto os usuários internos quanto os usuários externos das empresas (IUDÍCIBUS, 2015).

Dentro da abrangência desse assunto, a evidenciação sobre operações financeiras é de grande importância para o entendimento dos riscos e estratégias de uma empresa, visto que possibilita ao investidor ficar ciente das decisões financeiras da mesma. Conforme exposto na pesquisa realizada por Toigo, Brizolla e Fernandes (2015), o total dos instrumentos financeiros de uma empresa tem reflexo na sua saúde econômica, e a evidenciação sobre as operações com tais ativos/passivos garante maior certeza ao investidor quanto à tomada de decisões, permitindo haver maior controle sobre o tipo de estratégia de investimentos adotada pela entidade.

Segundo o CPC 39 (2009), instrumentos financeiros são quaisquer contratos que dêem origem a um ativo financeiro para a entidade e a um passivo financeiro ou instrumento patrimonial para o emissor. O referido pronunciamento contábil ainda traz a definição de ativo financeiro como abrangendo caixa, direitos contratuais e instrumentos patrimoniais de outras entidades, e de passivo financeiro como qualquer passivo que se enquadre como obrigação contratual envolvendo caixa ou ativos financeiros ou que se apresente como contrato a ser liquidado a partir de instrumentos patrimoniais da própria entidade.

Dentro do escopo de tais itens, têm-se os derivativos, conhecidos como tais pelo fato de terem seus valores sujeitos ao preço de outro ativo. Estes instrumentos podem ser usados para proteção dos ativos das empresas e antecipação garantida de preços futuros, através de operações para tais finalidades. O CPC $38(2009$, p. 8) traz a definição de derivativo como:

Instrumento financeiro ou outro contrato dentro do alcance deste Pronunciamento Técnico (ver itens 2 a 7) com todas as três características seguintes:

(a) o seu valor altera-se em resposta à alteração na taxa de juros especificada, preço de instrumento financeiro, preço de mercadoria, taxa de câmbio, índice de preços ou de taxas, avaliação ou índice de crédito, ou outra variável, desde que, no caso de variável não financeira, a variável não seja específica de uma parte do contrato (às vezes denominada "subjacente");

(b) não é necessário qualquer investimento líquido inicial ou investimento líquido inicial que seja inferior ao que seria exigido para outros tipos de contratos que se esperaria que tivessem resposta semelhante às alterações nos fatores de mercado; e (c) é liquidado em data futura.

Um dos tipos de instrumentos financeiros existentes no mercado são os instrumentos de hedge. No âmbito das operações puramente especulativas ou de arbitragem, as empresas possuem maior exposição à chance de perda de parte ou da totalidade de seus investimentos, e 
geralmente são adotadas estratégias de hedge. Brealey, Myers e Allen (2011) explicam que hedging envolve assumir um risco para diminuir o efeito de outro, sendo uma operação que diminui a exposição a oscilações inesperadas nos valores dos ativos, sejam elas boas ou ruins.

Existem algumas ferramentas usadas para hedge, como forwards, futuros e swaps, que junto com as opções são conhecidas como instrumentos derivativos. A partir desse tipo de operação, é possível proteger os ativos contra fatores de risco, como risco de mercado, de crédito, de liquidez, de moeda, de taxa de juros, entre outros.

O CPC 38 (2009) explana que "instrumento de hedge é um derivativo designado ou um ativo financeiro não derivativo designado ou um passivo financeiro não derivativo cujo valor justo ou fluxos de caixa se espera que compensem as alterações no valor justo ou nos fluxos de caixa de objeto de hedge designado".

Em conformidade, o CPC 38 (2009) afirma que o hedge pode ser feito com um instrumento derivativo ou com um instrumento não derivativo, adicionando que ambos os casos devem ser registrados pelo valor justo. Além disso, tal norma dita que as mudanças no valor do instrumento e do objeto de hedge não podem ser causadas por risco de crédito, mas sim pelo risco objeto de hedge. Também, os ativos usados como hedge não devem pertencer à empresa que os está usando para proteção, e deve ter alguma relação de ordem econômica com o objeto de hedge.

O CPC 40 (R1, 2012) prevê como as empresas deverão divulgar a descrição de cada tipo de hedge que possuir, descrição dos instrumentos financeiros usados como hedge e seus valores justos, além da natureza dos riscos objetos de hedge. Também deverá divulgar ganhos ou perdas sobre o instrumento de hedge e sobre o objeto de hedge.

Tais itens proporcionam uma evidenciação de maior qualidade, disponibilizando informações úteis para os usuários externos avaliarem as operações da empresa.

Diante da complexidade inerente à contabilização e evidenciação das operações de hedge, e considerando a relevância e atualidade do tema, o objetivo desta pesquisa é identificar o nível de evidenciação dos instrumentos de hedge nas companhias não financeiras de capital aberto brasileiras.

\section{Referencial Teórico}

Nesta seção está apresentada a fundamentação teórica da pesquisa, através da exposição dos temas diretamente relacionados à mesma, sendo dividida em evidenciação contábil, hedge e evidenciação e estudos semelhantes.

\subsection{Evidenciação Contábil}

Existem duas vertentes teóricas para a evidenciação contábil, a voluntária e a obrigatória. Enquanto a obrigatória tem caráter normativo, estipulando a obrigatoriedade da evidenciação de certos itens contábeis, a vertente voluntária prevê a divulgação voluntária de informações adicionais pela empresa, que complementem as obrigatórias (RUFINO; MONTE, 2014; HO; WONG, 2001; OLIVEIRA; LOPES; CUNHA, 2008).

Dye (2001) aborda a relação entre a teoria da evidenciação voluntária e a teoria dos jogos, afirmando que as empresas divulgam informações favoráveis a elas. A divulgação irá então ocorrer no sentido de aumentar o valor da empresa, e não o diminuir.

No Brasil, não havia previsão de obrigatoriedade para a evidenciação de instrumentos de hedge pelas companhias até o ano de 2009, quando foi lançado o CPC 40 (primeira versão no Brasil) que, baseado na norma internacional IFRS 7, trouxe o compromisso de as empresas 
divulgarem informações relacionadas a operações com instrumentos financeiros. Segundo o referido pronunciamento, "a entidade deve divulgar informações que permitam que os usuários de demonstrações contábeis avaliem a significância dos instrumentos financeiros para sua posição patrimonial e financeira e para a análise de desempenho" (CPC 40, 2009, item 7).

Em pesquisa realizada por Santos, Ponte e Mapurunga (2014) no primeiro ano após a obrigatoriedade da adoção das normas internacionais de contabilidade no Brasil, foi constatado que as empresas encontraram dificuldade em se adequar às regras por estas serem referentes a um sistema contábil diferente do que se costumava adotar no país. Além disso, houve um aumento no volume de informações obrigatórias a ser divulgado, o que levou as companhias a se esforçarem para se adaptarem à nova realidade estabelecida.

No que diz respeito à evidenciação de instrumentos de hedge, ainda há dificuldade em seguir integralmente as normas, dada a complexidade 'do tema'.

\subsection{Hedge e Evidenciação}

Instrumentos de hedge envolvem operações feitas com derivativos. Conforme Iudícibus (2013), o fato de os derivativos não exigirem desembolso inicial para investimento, ou o valor inicial do contrato for muito baixo faz com que tais instrumentos gerem alavancagem para os investidores, o que, dependendo da postura adotada, pode ser fator gerador de perdas.

De acordo com Assaf Neto (2001), existem três estratégias de investimentos usando derivativos, sendo elas especulação, arbitragem e hedging. Enquanto na especulação e na arbitragem o investidor se expõe a um risco considerável de perdas, através do hedging é possível minimizar tais perdas, gerando proteção para a carteira de investimentos.

Segundo Araújo (2011), "os hedgers atuam no mercado de derivativos com o objetivo de protegerem suas posições financeiras". Embora a especulação gere risco para uma empresa, Breadley, Myers e Allen (2011) afirmam que a presença de especuladores que estejam dispostos a aceitar riscos no mercado é necessária para disponibilizar a proteção que os hedgers procuram.

As operações de hedge são feitas a partir de negociações com instrumentos financeiros derivativos, como por exemplo, opções, forwards e futuros, que são usados pelas empresas em suas gestões de risco, ao proporcionarem proteção aos ativos contra riscos decorrentes da própria natureza dos mesmos, compensando as alterações de valor justo ou fluxo de caixa decorrentes do risco do próprio objeto de hedge (BREADLEY, MYERS E ALLEN, 2011).

Como um exemplo de operação de hedge, pode-se pensar em uma petrolífera que emite contratos de futuros fixando o preço do petróleo para o vencimento do papel, de forma que, mesmo se o valor da commoditie variar para mais ou para menos do previsto, a empresa receberá o estimado na data do lançamento dos títulos.

Dessa forma, os hedgers, ainda que protegidos, têm seus ativos sujeitos a riscos tais como de liquidez, de crédito, de moeda e de mercado. Nessa concepção, por envolverem riscos e configurarem operações complexas, o CPC 40 (2012, R1) dispõe sobre a evidenciação dos instrumentos de hedge, baseado na norma IFRS 9. Segundo o referido pronunciamento (2012, item 22), 


\section{REAVI}

Universidade do Estado de Santa Catarina

Centro de Educação Superior do Alto Vale do Itajaí

A entidade deve divulgar separadamente os itens a seguir para cada tipo de hedge descrito no Pronunciamento Técnico CPC 38 - Instrumentos Financeiros: Reconhecimento e Mensuração (isto é, hedge de valor justo, hedge de fluxo de caixa e hedge de investimento realizado no exterior):

(a) descrição de cada tipo de hedge;

(b) descrição dos instrumentos financeiros designados como instrumentos de hedge e seus valores justos na data das demonstrações contábeis; e

(c) a natureza dos riscos que estão sendo objeto do hedge.

O CPC 40 (R1, 2012) traz que as empresas devem proceder com a divulgação qualitativa e quantitativa de seus instrumentos financeiros, permitindo aos usuários obterem entendimento sobre a natureza dos riscos oriundos das operações com tais ativos e passivos.

No que diz respeito à divulgação qualitativa, a empresa deve divulgar sua exposição ao risco e seus objetivos e políticas para gerenciar os mesmos, bem como explicar seus métodos de mensuração. Por outro lado, a divulgação quantitativa envolve um "sumário de dados quantitativos sobre sua exposição aos riscos ao término do período de reporte" (CPC 40 (R1), 2012, p.13). Caso os dados quantitativos divulgados não representem a exposição da empresa ao risco durante o período, a empresa deve divulgar informações adicionais.

O referido pronunciamento (2012) ainda traz os requisitos para avaliação da eficácia do hedge. Um hedge é considerado altamente eficaz se consegue compensar as variações do valor justo ou fluxo de caixa decorrentes do risco para o qual foi designado e se seus resultados reais se enquadram dentro do intervalo de $80 \%$ a $125 \%$. Tal eficácia é avaliada pelo menos no fechamento das demonstrações contábeis anuais ou intermediárias.

Segundo exposto por Lopes e Santos (2003), a eficácia de uma operação de hedge pode ser medida através da correlação ou grau de relacionamento entre o instrumento de hedge e o objeto do mesmo. Tal medida deve ser negativa, de forma que o crescimento de uma variável será exatamente o oposto do crescimento da segunda variável.

O hedge pode ser registrado por seu valor justo ou fluxo de caixa, sendo cada método adequado para diferentes operações. As diferenças entre os tratamentos contábeis envolvem principalmente o momento da contabilização do valor do instrumento.

Pode-se tomar como exemplo o registro de ganhos sobre o hedge, que são contabilizados diretamente no resultado quando se tratar de hedge de valor justo, e no Patrimônio Líquido, quando o hedge for de fluxo de caixa.

Diante do exposto, considerando a complexidade e importância dos instrumentos de hedge nas empresas, ressalta-se a relevância da evidenciação contábil dos procedimentos que envolvem seus riscos, sua eficácia e sua política de aplicação.

\subsection{Estudos Semelhantes}

Para a elaboração desta pesquisa, foram levantados estudos realizados em anos anteriores, a fim de que pudesse ser estabelecida uma base de pesquisa para o artigo. Como parâmetro para a seleção dos trabalhos anteriores, realizou-se um levantamento na base Scientific Periodicals Electronic Library (SPELL) no dia 08/05/2016, utilizando-se as palavras-chave: instrumentos financeiros e hedge.

A partir do levantamento realizado, foram encontrados 71 artigos. Destes, eram semelhantes a esta pesquisa 7 trabalhos, possuindo como abordagem principal evidenciação de instrumentos financeiros. O Quadro 1 demonstra os trabalhos semelhantes encontrados conforme a metodologia adotada. 
Quadro 1: Estudos semelhantes

\begin{tabular}{|c|c|c|}
\hline Autores/Ano & Objetivo/Período analisado & Resultados /Conclusões \\
\hline Costa Junior (2003) & $\begin{array}{l}\text { "Levantar o quadro atual da política de } \\
\text { evidenciação de instrumentos } \\
\text { financeiros por parte das companhias } \\
\text { abertas no Brasil, através de suas } \\
\text { demonstrações contábeis". Período } \\
\text { analisado: } 2000 \text {. }\end{array}$ & $\begin{array}{l}\text { Constatou-se } \text { que as companhias } \\
\text { abertas no Brasil não prestam } \\
\text { informações adequadas em suas } \\
\text { demonstrações contábeis, no que } \\
\text { concerne aos instrumentos } \\
\text { financeiros. }\end{array}$ \\
\hline $\begin{array}{l}\text { Darós } \\
(2005)\end{array}$ & $\begin{array}{l}\text { "Analisar como as operações com } \\
\text { instrumentos financeiros derivativos } \\
\text { vêm sendo evidenciadas nas } \\
\text { Demonstrações Contábeis de empresas } \\
\text { brasileiras não financeiras", tendo por } \\
\text { base o ano de } 2002 \text {. }\end{array}$ & $\begin{array}{l}\text { Constatou-se que a grande maioria das } \\
\text { empresas não atende às determinações } \\
\text { da CVM e não evidencia, conforme } \\
\text { requerido, as informações referentes } \\
\text { às suas operações envolvendo } \\
\text { derivativos. }\end{array}$ \\
\hline $\begin{array}{l}\text { Murcia } \\
(2009)\end{array}$ & $\begin{array}{l}\text { "Analisar o impacto da Deliberação } \\
\text { CVM no. 566/08 e da Instrução CVM } \\
\mathrm{n}^{\mathrm{o}} \text {. 475/08 no disclosure de } \\
\text { informações de operações com } \\
\text { instrumentos financeiros derivativos } \\
\text { das companhias abertas no Brasil". } \\
\text { Período: } 2007 \text { e } 2008 .\end{array}$ & $\begin{array}{l}\text { Os autores descobriram uma melhora } \\
\text { no disclosure das empresas, embora } \\
\text { estas ainda não divulguem } \\
\text { integralmente todas as informações } \\
\text { exigidas pelas normas. }\end{array}$ \\
\hline $\begin{array}{l}\text { Peixoto e Malaquias } \\
(2012)\end{array}$ & $\begin{array}{l}\text { "Analisar o nível de evidenciação que } \\
\text { as empresas brasileiras de capital } \\
\text { aberto fornecem em seus relatórios } \\
\text { contábeis; mais especificamente, foi } \\
\text { analisado o impacto da convergência } \\
\text { contábil no citado nível de } \\
\text { evidenciação". Período: } 2005-2010 \text {. }\end{array}$ & $\begin{array}{l}\text { Os autores constataram um } \\
\text { considerável aumento na evidenciação } \\
\text { dos derivativos, porém as empresas } \\
\text { continuaram não fornecendo de forma } \\
\text { completa todas as informações } \\
\text { requeridas pelo instrumento de coleta } \\
\text { de dados utilizado. }\end{array}$ \\
\hline $\begin{array}{l}\text { Malaquias e Lemes } \\
(2013)\end{array}$ & $\begin{array}{l}\text { "Analisar o nível de disclosure das } \\
\text { demonstrações financeiras de empresas } \\
\text { brasileiras em relação aos } \\
\text { requerimentos dispostos pelo IASB } \\
\text { (InternationalAccounting Standards } \\
\text { Board) para evidenciação de } \\
\text { instrumentos financeiros". Período: } \\
2002-2006\end{array}$ & $\begin{array}{l}\text { Os autores constataram que a média } \\
\text { de evidenciação das empresas } \\
\text { brasileiras possui r média } \\
\text { estatisticamente inferior ao dos } \\
\text { relatórios fornecidos ao mercado } \\
\text { norte-americano. evidenciação. }\end{array}$ \\
\hline Ambrozini (2014) & $\begin{array}{l}\text { "Avaliar o grau de observância das } \\
\text { orientações de evidenciação de } \\
\text { instrumentos financeiros derivativos } \\
\text { emanadas pelo CPC } 40 \text { (R1) por parte } \\
\text { das companhias abertas brasileiras com } \\
\text { ações negociadas na Bolsa de Valores } \\
\text { de São Paulo". Período: } 2013\end{array}$ & $\begin{array}{l}\text { Foi constatado que o grau de } \\
\text { evidenciação dos derivativos nas } \\
\text { demonstrações contábeis } \\
\text { empresas brasileiras sofreu uma } \\
\text { considerável melhora após a } \\
\text { introdução das normas IFRS. }\end{array}$ \\
\hline $\begin{array}{l}\text { Toigo, Brizolla e } \\
\text { Fernandes }(2015)\end{array}$ & $\begin{array}{l}\text { "Analisar as características de } \\
\text { governança corporativa e financeiras } \\
\text { que discriminam grupos de empresas } \\
\text { que adotam hedge accounting no novo } \\
\text { mercado para gestão de risco". } \\
\text { Período: } 31 / 12 / 2012 \text {. }\end{array}$ & $\begin{array}{l}\text { As companhias brasileiras } \\
\text { pertencentes ao novo mercado que } \\
\text { adotam a prática de disclosure para } \\
\text { demonstrar aprimoramento na gestão } \\
\text { de risco dos investimentos dos } \\
\text { acionistas, são empresas de grande } \\
\text { porte com a estrutura de capital } \\
\text { composta por investidor estrangeiro e } \\
\text { representativa concentração acionária. }\end{array}$ \\
\hline
\end{tabular}

FONTE: Elaborado pelos autores. 
Em uma análise geral, pode-se observar nos estudos selecionados que, embora o nível de evidenciação de instrumentos financeiros (incluindo os de hedge) tenha aumentado após a adoção das normas internacionais de contabilidade no Brasil, ainda não existe uma completa adesão das companhias com relação à evidenciação das referidas ferramentas financeiras.

\section{Metodologia} pesquisa.

Nesta seção está apresentada a metodologia utilizada para atingir o objetivo desta

\subsection{Delineamento da Pesquisa}

A presente investigação se enquadra como documental, no que diz respeito aos procedimentos de coleta de dados, uma vez que as informações para a pesquisa foram obtidas nas Notas Explicativas, Formulário de Referência e Relatório da Administração de cada companhia componente da amostra. Tais documentos, de acordo com Gil (2002), constituem "documentos de segunda mão", ou fontes secundárias, uma vez que foram analisados previamente por outro agente.

Quanto aos objetivos, esta pesquisa pode ser enquadrada como descritiva, uma vez que para atingir o objetivo desta pesquisa foi necessário descrever o nível de evidenciação de operações com instrumentos de hedge.

No que tange a abordagem do problema, o estudo é qualitativo. Segundo Gil (2002), pode-se definir o processo de análise qualitativo como "uma sequência de atividades, que envolve a redução dos dados, a categorização desses dados, sua interpretação e a redação do relatório". Ou seja, os dados são transformados em informações e organizados de forma que embasem a elaboração de uma conclusão acerca dos mesmos quando interpretados.

\subsection{Instrumento de Pesquisa}

A fim de atender o objetivo desta investigação, foi elaborada uma lista de verificação com as categorias de análise de itens considerados obrigatórios para evidenciação dos instrumentos de hedge pelas companhias. A referida lista foi baseada nas disposições sobre o assunto contidas no pronunciamento contábil CPC 40 (R1, 2012), que trata sobre evidenciação de instrumentos financeiros, nos aspectos de evidenciação em específico para o hedge, que são abordados nos itens 22, 23 e 24.

Quadro 2: Categorias de análise

\begin{tabular}{|l|}
\hline Para cada tipo de hedge \\
\hline Descrição de cada tipo de hedge. \\
\hline $\begin{array}{l}\text { Descrição dos instrumentos financeiros designados como instrumentos de hedge e seus valores } \\
\text { justos na data das demonstrações contábeis. }\end{array}$ \\
\hline A natureza dos riscos que estão sendo objeto do hedge. \\
\hline Para hedges de fluxo de caixa, a entidade deve divulgar \\
\hline $\begin{array}{l}\text { Os períodos em que se espera que o fluxo de caixa irá ocorrer e quando espera-se que eles afetarão } \\
\text { o resultado. }\end{array}$ \\
\hline $\begin{array}{l}\text { Uma descrição de qualquer operação prevista em que foi utilizada a contabilidade de hedge, mas } \\
\text { que já não se espera que ocorra. }\end{array}$ \\
\hline $\begin{array}{l}\text { Uma descrição de qualquer operação prevista em que foi utilizada a contabilidade de hedge, mas } \\
\text { que já não se espera que ocorra. }\end{array}$ \\
\hline
\end{tabular}

R. Eletr. do Alto Vale do Itajaí - REAVI, v. 7, n. 10, p. 01-15, jun., 2018 
A quantia que tenha sido reclassificada do patrimônio líquido para o resultado do período, mostrando o montante incluído em cada item da demonstração do resultado abrangente.

O montante que tenha sido removido do patrimônio líquido durante o período e incluído no custo inicial ou outro valor contábil de ativo não financeiro ou passivo não financeiro cuja aquisição ou incorrência tenha sido um hedge de operação prevista e altamente provável.

\section{A entidade deve divulgar separadamente}

Em hedges de valor justo, ganhos ou perdas:

(i) sobre o instrumento de hedge.

(ii) sobre o objeto de hedge atribuído ao risco coberto.

A ineficácia do hedge reconhecida no resultado que decorre de hedges de fluxo de caixa.

FONTE: Elaborado pelos autores com base nas disposições do CPC 40 (R1, 2012).

A relação de itens demonstrada no Quadro 2 foi aplicada na coleta dos dados, que foi realizada separadamente a partir das Notas Explicativas e Demonstrações Financeiras, Formulário de Referência e Relatório da Administração de cada companhia, disponíveis nos respectivos sites de Relações com Investidores. Analisando os itens que constam no CPC 40 (R1, 2012), foi possível identificar as companhias que evidenciaram de maneira mais detalhada os instrumentos de hedge.

Adicionalmente, foi verificado se as companhias seguem a instrução CVM 475/2008, que dispõe sobre a divulgação da análise de sensibilidade nas Notas Explicativas para cada tipo de risco de mercado originado por instrumentos financeiros e que sejam considerados relevantes pela administração.

Segundo a referida instrução, o instrumento e o objeto de hedge devem ser divulgados à parte no quadro de sensibilidade, "de modo a informar sobre a exposição líquida da companhia, em cada um dos três cenários mencionados no art. $3^{\circ}, \S 2^{\circ}$ " (CVM 475/2008, p.2), ou seja, deve ser divulgado o cenário esperado pela administração e outros dois, com deterioração de $25 \%$ e $50 \%$ na variável de risco considerada. Dessa maneira, foi analisado se as companhias da amostra divulgaram os seguintes itens constantes no $\S 1^{\circ}$ do art. $3^{\circ}$ :

I - identificar os tipos de risco que podem gerar prejuízos materiais para a companhia, incluídas as operações com instrumentos financeiros derivativos originadoras desses riscos;

II - discriminar os métodos e premissas usadas na preparação da análise de sensibilidade;

III - definir o cenário mais provável, na avaliação da administração, além de 2 (dois) cenários que, caso ocorram, possam gerar resultados adversos para a companhia;

IV - estimar o impacto dos cenários definidos no valor justo dos instrumentos financeiros operados pela companhia; e

V - elaborar o demonstrativo de análise de sensibilidade em forma de tabela, considerando os instrumentos financeiros relevantes, inclusive os derivativos, e os riscos selecionados, em linhas, e os cenários definidos, em colunas.

A norma se aplica a todos os instrumentos financeiros da companhia, sendo ou não reconhecidos como Ativos ou Passivos, e demonstra cenários prováveis em relação aos instrumentos financeiros, além de situações de deterioração dos riscos dos mesmos. No âmbito desta pesquisa, a verificação da análise de sensibilidade foi restrita à divulgação relacionada a instrumentos derivativos para fins de hedge. 


\subsection{Procedimentos de Pesquisa}

Nesta etapa, é procedida a coleta de dados a partir das Demonstrações Financeiras e Notas Explicativas, Formulário de Referência e Relatório da Administração das empresas selecionadas para a amostra, tendo como ano base o de 2015. A análise do nível de evidenciação foi realizada separadamente para cada relatório, dessa maneira foi possível conhecer o principal meio que as companhias utilizam para divulgar as informações sobre os instrumentos de hedge.

Segundo Marconi e Lakatos (2003, p.165), a coleta de dados é a "etapa da pesquisa em que se inicia a aplicação dos instrumentos elaborados e das técnicas selecionadas, a fim de se efetuar a coleta dos dados previstos".

A fim de se mensurar a evidenciação da contabilidade de hedge pelas companhias e a conformidade das mesmas em relação ao exigido no CPC 40 (R1), foi utilizado um indicador de evidenciação em termos percentuais, o qual pode ser calculado por meio da seguinte fórmula:

Nível de evidenciação $=\underline{\text { Total de itens divulgados pela companhia }} \times 100$

(Total de itens da lista - NA)

Para cada item divulgado, foi atribuído 1 (um), e para cada item não divulgado foi atribuído 0 (zero). No caso de um fator não se aplicar a determinada companhia, atribuiu-se o conceito NA ("não se aplica"), que tem por finalidade excluir do cálculo o número de itens da lista que não se enquadram na situação da empresa porque ela informa não possuir tal responsabilidade ou nas situações em que a mesma nada informou, não havendo condições de saber se ela estaria ou não obrigada a divulgar o item. Essa mesma metodologia foi utilizada na pesquisa de Souza (2015).

A partir desta metodologia, foi possível calcular o nível de evidenciação de cada companhia sobre os derivativos designados como operações de hedge, dividindo-se o total de itens divulgados pelo número de itens aplicáveis constantes na lista. Ressalta-se que o nível de evidenciação, a partir do índice, foi verificado apenas a partir das Demonstrações Financeiras e Notas explicativas, visto que estes são relatórios que devem atender as exigências de divulgação do CPC 40 (R1).

Dessa forma, apesar de analisados também o Relatório da Administração e Formulário de Referência, estes não serviram de parâmetro para cálculo do índice de evidenciação, visto que não estão submetidos à exigibilidade do CPC 40 (R1). Os resultados obtidos são apresentados sob a forma de gráficos e tabelas, dispostos na próxima seção deste artigo.

\subsection{Amostra de Pesquisa}

A seleção das empresas para a amostragem foi feita através do software Economática ${ }^{\circledR}$. A amostra foi delimitada excluindo-se as instituições financeiras, uma vez que as operações das mesmas já pressupõem o uso de operações de hedge.

Dentre todas as companhias não financeiras listadas na Bolsa de Valores, Brasil, Bolsa, Balcão (B3), foram escolhidas as vinte maiores em termos de Ativo Total, sendo as mesmas dispostas no Quadro 3. 
Quadro 3: Empresas analisadas

\begin{tabular}{|l|r|l|r|}
\hline Empresa & Ativo Total* $(2015)$ & Empresa & Ativo Total* $(2015)$ \\
\hline Petrobras & 900.135 .000 & Sid Nacional & 48.649 .974 \\
\hline Vale & 345.549 .435 & P.Acucar-Cbd & 47.502 .000 \\
\hline Eletrobras & 149.645 .408 & Embraer & 45.566 .910 \\
\hline JBS & 121.752 .954 & Dufry Ag & 41.044 .598 \\
\hline Telef Brasil & 101.685 .064 & Cemig & 40.879 .964 \\
\hline Oi & 97.014 .806 & CPFL Energia & 40.532 .471 \\
\hline Ambev S/A & 90.176 .234 & BRF S.A. & 40.388 .014 \\
\hline Gerdau Met. & 70.218 .773 & Tim Part S/A & 35.403 .652 \\
\hline Braskem & 59.961 .294 & Cosan & 30.382 .191 \\
\hline Itausa & 54.830 .000 & Cielo & 29.977 .801 \\
\hline
\end{tabular}

FONTE: Economática ${ }^{\circledR} \quad *$ Valores expressos em milhares de reais

$\mathrm{Na}$ ordem de seleção da amostra, conforme os critérios adotados nesta pesquisa, foram ignoradas as companhias Gerdau e Sabesp, uma vez que não foi possível analisar os dados das mesmas. No caso da Sabesp, o impedimento de caracterizou pela companhia não realizar operações de hedge, e a Gerdau, por ser controlada por outra empresa da amostra, não apresentou demonstrativos em separado da controladora. Em tais situações, a coleta de dados foi prosseguida com a empresa seguinte em termos de Ativo total.

Feita a seleção da amostra, foram coletadas as Notas Explicativas, Formulário de Referência e Relatório da Administração referentes ao exercício de 2015 de cada companhia constante no Quadro 3, nos respectivos sites de Relações com Investidores. Desta forma, foi verificado um total de sessenta (60) documentos contábeis. A partir dos mesmos, foram analisados os itens constantes na Lista de Verificação exposta no Quadro 2.

\section{Análise dos Resultados}

Nesta seção estão apresentados os resultados da presente pesquisa.

\subsection{Análise do Nível de Evidenciação}

O objetivo da presente pesquisa foi identificar o nível de evidenciação dos instrumentos de hedge nas companhias não financeiras de capital aberto brasileiras. Dessa maneira, na Tabela 1 está apresentado o resultado relativo ao nível de evidenciação calculado para a amostra de pesquisa a partir das Demonstrações Financeiras e Notas Explicativas.

Tabela 1 - Nível de evidenciação da amostra analisada

\begin{tabular}{c|c|c|c}
\hline Empresa & Nível de evidenciação & Empresa & Nível de evidenciação \\
\hline Petrobras & $100 \%$ & Sid Nacional & $57 \%$ \\
\hline Telef Brasil & $100 \%$ & Gerdau Met & $50 \%$ \\
\hline Eletrobras & $80 \%$ & Itausa & $50 \%$ \\
\hline JBS & $80 \%$ & Cosan & $50 \%$ \\
\hline Ambev S/A & $80 \%$ & P.Acucar-Cbd & $40 \%$ \\
\hline BRF AS & $75 \%$ & Dufry Ag & $40 \%$ \\
\hline
\end{tabular}

R. Eletr. do Alto Vale do Itajaí - REAVI, v. 7, n. 10, p. 01-15, jun., 2018 


\begin{tabular}{c|c|c|c}
\hline Cielo & $67 \%$ & Embraer & $30 \%$ \\
\hline Oi & $63 \%$ & Tim Part S/A & $25 \%$ \\
\hline Braskem & $63 \%$ & Cemig & $10 \%$ \\
\hline Vale & $60 \%$ & CPFL Energia & $10 \%$ \\
\hline \multicolumn{2}{|c}{$\mathbf{5 6 \%}$} \\
\hline
\end{tabular}

FONTE: Dados de pesquisa

A partir do cálculo efetuado para cada empresa, pode-se chegar a uma média do nível de evidenciação da amostra, que ficou em $56 \%$. Apesar de duas empresas terem atingido o máximo da evidenciação exigida pelo CPC 40 (R1), nove empresas divulgaram apenas metade ou menos dos itens requeridos.

As cinco empresas com melhor nível de evidenciação apresentaram índice igual ou superior a 0,80 . As cinco empresas da amostra com pior medida do nível de evidenciação apresentaram valores para o mesmo entre 0,10 e 0,40. A fim de expandir o campo de visualização sobre os níveis de evidenciação calculados, o Gráfico 1 apresenta os resultados para todas as 20 empresas analisadas nesta pesquisa.

\section{Gráfico 1: Nível de Evidenciação}

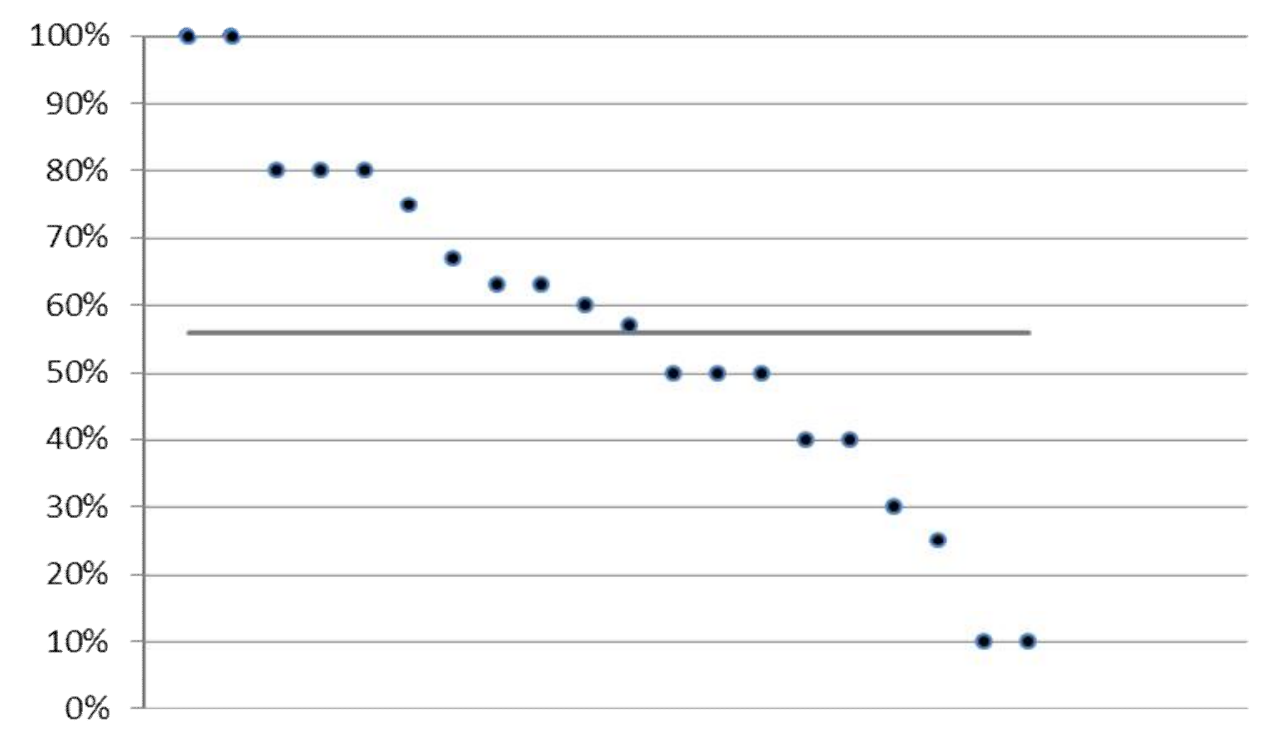

FONTE: Dados de pesquisa

A partir do Gráfico 1 é possível visualizar a dispersão dos valores encontrados para o nível de evidenciação das empresas. A partir da média, cujo valor foi calculado em 0,56 , notase que os valores do nível de evidenciação se encontram distribuídos de forma praticamente igual acima e abaixo da linha média, sendo a concentração de onze empresas com nível acima de 0,56 e nove com nível abaixo deste valor.

\subsection{Análise Comparativa entre as Informações Divulgadas}

Adicionalmente às Demonstrações Financeiras e Notas Explicativas, foram também analisados o Formulário de Referência e o Relatório da Administração. As informações divulgadas em cada relatório podem ser visualizadas de forma comparativa na Tabela 2 . Os 
números indicam o percentual de empresas que atendem a divulgação de cada item da lista de verificação.

Tabela 2 - Comparação da evidenciação entre Demonstrativos

\begin{tabular}{l|c|c|c}
\multicolumn{1}{c|}{ Para cada tipo de hedge } & $\begin{array}{c}\text { Notas } \\
\text { Explicativas }\end{array}$ & $\begin{array}{c}\text { Formulário de } \\
\text { Referência }\end{array}$ & $\begin{array}{c}\text { Relatório da } \\
\text { Administração }\end{array}$ \\
\hline Descrição de cada tipo de hedge & $70 \%$ & $40 \%$ & $10 \%$ \\
\hline $\begin{array}{l}\text { Descrição dos instrumentos financeiros designados como } \\
\text { instrumentos de hedge e seus valores justos na data das } \\
\text { demonstrações contábeis }\end{array}$ & $80 \%$ & $55 \%$ & $5 \%$ \\
\hline A natureza dos riscos que estão sendo objeto do hedge & $100 \%$ & $85 \%$ & $15 \%$ \\
\hline
\end{tabular}

Fonte: Dados de pesquisa

Na pesquisa foi possível verificar que no Formulário de Referência e no Relatório da Administração são divulgadas informações de cunho mais qualitativo, possivelmente porque tais documentos não visam um aprofundamento nas questões mais técnicas da contabilidade. Dessa forma, foi aplicada na análise de tais documentos apenas a primeira parte da Lista de Verificação apresentada no Quadro 2, que diz respeito à descrição dos riscos e de cada tipo de hedge.

Em comparação com os referidos relatórios, as Notas Explicativas apresentam uma maior quantidade de divulgação relacionada ao hedge, possivelmente pelo fato de haver previsão normativa para a evidenciação de tais instrumentos financeiros nas mesmas, o que sugere que a determinação legal exerce influência sobre a evidenciação.

Nas Notas Explicativas foram também divulgadas as análises de sensibilidade das empresas, conforme requisito da instrução CVM 475/2008. A partir do disposto em tal norma, foram analisadas as informações divulgadas pelas companhias, em que se constatou que $75 \%$ das mesmas atende a todas as disposições da referida norma.

Em geral, as companhias que não cumpriram em sua totalidade as exigências da referida norma fazem parte das dez empresas com menor ativo da amostra, e efetuaram os cenários que possam gerar resultados negativos à companhia sem usar os dois cenários com situação de deterioração dos instrumentos financeiros, de pelo menos $25 \%$ e $50 \%$.

Em relação à análise da sensibilidade, o maior problema encontrado foi a divulgação incompleta dos cenários possíveis de deterioração nas variáveis de risco causadas pelo uso de instrumentos financeiros.

\subsection{Análise Nível de Evidenciação e Total do Ativo}

A Tabela 3 mostra a disposição das empresas da amostra segundo o total do ativo, trazendo também o nível de evidenciação de cada uma.

Tabela 3 - Nível de evidenciação e total do Ativo

\begin{tabular}{|c|c|c|c|c|c|}
\hline Empresa & $\begin{array}{c}\text { Ativo } \\
(\mathrm{mil} \mathrm{R} \$)\end{array}$ & $\begin{array}{c}\text { Nível de } \\
\text { Evidenciação }\end{array}$ & Empresa & $\begin{array}{c}\text { Ativo } \\
(\mathrm{mil} \mathrm{R} \$)\end{array}$ & $\begin{array}{c}\text { Nível de } \\
\text { Evidenciação }\end{array}$ \\
\hline Petrobras & 900.135 .000 & $100 \%$ & Sid Nacional & 48.649 .974 & $57 \%$ \\
\hline Telef Brasil & 101.685 .064 & $100 \%$ & Itausa & 54.830 .000 & $50 \%$ \\
\hline Eletrobras & 149.645 .408 & $80 \%$ & Cosan & 30.382 .191 & $50 \%$ \\
\hline JBS & 121.752 .954 & $80 \%$ & Gerdau Met & 70.218 .773 & $50 \%$ \\
\hline Ambev S/A & 90.176 .234 & $80 \%$ & P.Acucar-Cbd & 47.502 .000 & $40 \%$ \\
\hline
\end{tabular}




\begin{tabular}{l|c|c|c|c|c}
\hline \multicolumn{1}{c|}{ Empresa } & $\begin{array}{c}\text { Ativo } \\
(\mathrm{mil} \mathrm{R \$ )}\end{array}$ & $\begin{array}{c}\text { Nível de } \\
\text { Evidenciação }\end{array}$ & Empresa & $\begin{array}{c}\text { Ativo } \\
(\text { mil R\$) }\end{array}$ & $\begin{array}{c}\text { Nível de } \\
\text { Evidenciação }\end{array}$ \\
\hline BRF AS & 40.388 .014 & $75 \%$ & Dufry Ag & 41.044 .598 & $40 \%$ \\
\hline Cielo & 29.977 .801 & $67 \%$ & Embraer & 45.566 .910 & $30 \%$ \\
\hline Oi & 97.014 .806 & $63 \%$ & Tim Part S/A & 35.403 .652 & $25 \%$ \\
\hline Braskem & 59.961 .294 & $63 \%$ & Cemig & 40.879 .964 & $10 \%$ \\
\hline Vale & 345.549 .435 & $60 \%$ & CPFL Energia & 40.532 .471 & $10 \%$ \\
\hline
\end{tabular}

Fonte: Dados de pesquisa

Dentre as dez empresas com maior nível de evidenciação, oito estão dentre as que possuem maior ativo. A empresa com maior nível de evidenciação corresponde a que tem o maior ativo total. Da mesma forma, as empresas que apresentam os menores valores para o nível de evidenciação são aquelas que possuem os menores valores para Ativo dentro da amostra, porém a empresa com o menor nível de evidenciação não é a que apresenta menor Ativo.

A partir de tal análise, pode ser observada uma tendência de maior evidenciação dos instrumentos de hedge quanto maior for o Ativo da companhia. O estudo de Malaquias, Lemes (2013), que analisou o nível de evidenciação de instrumentos financeiros de empresas brasileiras de acordo com os requerimentos do IASB, também verificou a existência de uma relação positiva entre o tamanho das empresas e o seu nível de evidenciação.

Segundo o estudo, para essas empresas pode haver relação com a teoria de que as mesmas podem gerar informações mais detalhadas com menor custo.

\section{Considerações Finais}

O objetivo desta pesquisa foi identificar o nível de evidenciação dos instrumentos de hedge nas companhias não financeiras de capital aberto brasileiras. A partir dos resultados da pesquisa, verificou-se que os maiores níveis de evidenciação foram apresentados, em sua maioria, pelas companhias da amostra que possuíam um maior ativo total.

Dentre os documentos analisados nesta pesquisa, as Demonstrações Financeiras e Notas Explicativas foram os que mais apresentaram as informações requisitadas nas normas contábeis, provavelmente pela obrigatoriedade de divulgação em tais demonstrativos.

Nas Notas Explicativas foram divulgadas informações de forma bastante detalhada, abrangendo aspectos qualitativos e quantitativos, enquanto que no Relatório da Administração e Formulário de Referência as informações divulgadas possuíam cunho mais qualitativo. $\mathrm{O}$ Formulário de Referência foi o relatório com menos informações em relação às operações de hedge.

Os resultados desta pesquisa demonstram uma possível evolução na evidenciação em notas explicativas pertinentes aos instrumentos de hedge por parte das companhias analisadas. Estes achados vão ao encontro dos estudos de Murcia e Santos (2009) e Peixoto e Malaquias (2012) que constaram uma possível tendência de melhorias na divulgação realizada pelas companhias brasileiras.

A divulgação ampla das operações com instrumentos financeiros de uma empresa garante maior transparência nas demonstrações contábeis e auxiliam os investidores na tomada de decisões.

Ressalta-se que as conclusões obtidas a partir do presente estudo estão limitadas à amostra e ao período analisado, não podendo ser generalizadas para outras companhias ou períodos diferentes. A partir do estudo realizado, sugere-se como proposta para estudos

R. Eletr. do Alto Vale do Itajaí - REAVI, v. 7, n. 10, p. 01-15, jun., 2018 
posteriores uma análise do nível de evidenciação e mensuração dos instrumentos de hedge para instituições financeiras considerando suas peculiaridades e normatização específica do setor.

\section{Referências}

AMBROZINI, M. A. Análise do grau de evidenciação das operações com instrumentos financeiros derivativos pelas companhias brasileiras listadas no Ibovespa. Revista Contemporânea de Contabilidade, Florianópolis, v. 11, n. 24, p.25-42, 2014.

ASSAF NETO, A. Mercado Financeiro. 4.ed. 356p. São Paulo: Atlas, 2001.

Black; Scholes. The Pricing of Option and Corporate Liabilities. Journal of Political economy, 81, p. 637-659.

ARAUJO, C. G.; IKUNO, L. M.; PAULO, E; SALES, I. C. H. Hedge accounting: análise da extensão de sua utilização nas empresas brasileiras que compõem o IBRX-100. $11^{\circ}$ Congresso USP de Controladoria e Contabilidade. Anais... São Paulo/SP 28 e 29 julho de 2011.

BREALEY, R. A.; MYERS, S. C.; ALLEN, F. Principles of corporate finances. 10. ed. Nova Iorque: Mcgraw-hill Irwin, 2011.

COMITÊ DE PRONUNCIAMENTOS CONTÁBEIS (CPC). CPC 38 - Instrumentos Financeiros: Reconhecimento e mensuração. 2009. Disponível em: < http://static.cpc.mediagroup.com.br/Documentos/406_CPC_38_rev\%2006.pdf $>$. Acesso em: 19 maio de 2016.

COMITÊ DE PRONUNCIAMENTOS CONTÁBEIS (CPC). CPC 39 - Instrumentos

Financeiros: Apresentação. 2009. Disponível em: < http://static.cpc.mediagroup.com.br/Documentos/410_CPC_39_rev\%2006.pdf $>$.

Acesso em: 19 maio de 2016.

COMITÊ DE PRONUNCIAMENTOS CONTÁBEIS (CPC). CPC 40 (R1) - Instrumentos Financeiros: $\quad$ Evidenciação. 2012. Disponível em: http://static.cpc.mediagroup.com.br/Documentos/418_CPC_40_R1_rev\%2008.pdf $>$. Acesso em: 19 maio de 2016.

COSTA JUNIOR, J. V. Uma avaliação do nível de evidenciação das companhias abertas, no Brasil, no tocante aos instrumentos financeiros. Revista Contabilidade \& Finanças, São Paulo, v. 14, n. 32, p.23-39, 2003.

DARÓS, L. L.; BORBA, J. A. Evidenciação de instrumentos financeiros derivativos nas demonstrações contábeis: uma análise das empresas brasileiras. Revista Contabilidade \& Finanças - USP, São Paulo, n. 39, p.68-80, 2005.

DYE, R. A. An evaluation on "essays on disclosure" and the disclosure literature in accounting. Journal Of Accounting And Economics. Evanston, p. 181-235. mar. 2001.

GIL, A. C. Como elaborar projetos de pesquisa. 4. Ed. São Paulo: Atlas, 2002. 
HENDRIKSEN, E. S.; VAN BREDA, M. F. Teoria da contabilidade. 5. ed. São Paulo: Atlas, 1999.

IUDÍCIBUS, S. et al. Manual de contabilidade societária: Aplicável a todas as Sociedades de acordo com as Normas Internacionais e do CPC. 2. ed. São Paulo: Atlas, 2013.

LOPES, A. B.; SANTOS, N. S. A administração do lucro contábil e os critérios para determinação da eficácia do hedge accounting: utilização da correlação simples dentro do arcabouço do sfas $n^{0}$ 133. Revista Contabilidade e Finanças, São Paulo, v. 14, n. 31, p.16$25,2003$.

LOPES, J. L. G.; SCHIOZER, R. F.; SHENG, H. H. Hedge e especulação com Derivativos Cambiais: evidências de operações cotidianas. Revista de Administração Contemporânea, Rio de Janeiro, v. 17, n. 4, p.438-458, 2013.

MALAQUIAS, R. F.; LEMES, S. Disclosure de instrumentos financeiros segundo as normas internacionais de contabilidade: evidências empíricas de empresas brasileiras. Brazilian Business Review, Vitória, v. 10, n. 3, p.85-112, 2013.

MURCIA, F. D.; SANTOS, A. D. Regulação contábil e a divulgação de informações de operações com instrumentos financeiros derivativos: analise do impacto da CVM No 566/08 e da CVM No 475/08 no disclosure das companhias abertas no Brasil. Revista de Contabilidade e Organizações, v. 3, n. 6, art. 1, p. 3-21, 2009.

PEIXOTO, F.; MALAQUIAS, R. F. O impacto da convergência contábil na evidenciação dos instrumentos financeiros derivativos das empresas brasileiras. Revista de Gestão, Finanças e Contabilidade, Salvador, v. 2, n. 1, p.39-55, 2012.

RUFINO, M. A.; MONTE, P. A. Fatores que Explicam a Divulgação Voluntária das 100 Empresas com Ações Mais Negociadas na BM\&FBOVESPA; Sociedade, Contabilidade e Gestão, Rio de Janeiro, v. 9, n. 3, p.59-75, 2014.

SANTOS, E. S.; PONTE, V. M. R.; MAPURUNGA, P. V. R. Adoção Obrigatória do IFRS no Brasil (2010): Índice de Conformidade das Empresas com a Divulgação Requerida e Alguns Fatores Explicativos. Revista Contabilidade \& Finanças, São Paulo, v. 25, n. 65, p.161-176, 2014.

SOUZA, M. M. Value relevance do nível de disclosure das combinações de negócios e do goodwill reconhecido nas empresas brasileiras. 2015. 183 p. Tese (Doutorado em Administração) - Programa de Pós-Graduação em Administração, Universidade Federal de Santa Catarina. Florianópolis, 2015.

TOIGO, L. A.; BRIZOLLA, M. M.; FERNANDES, Francisco Carlos. Características Determinantes das Companhias do Novo Mercado que Adotam o Hedge Accounting. Sociedade, Contabilidade e Gestão, Rio de Janeiro, v. 10, n. 2, p.6-22, 2015. 